\title{
Calculation of the Average Dose Rate for Linear Gamma-Radiation Sources
}

\author{
G. Z. Gochaliev \\ Karpov Institute of Physical Chemistry, Obninsk Branch, Obninsk, Kaluga oblast, 249033 Russia \\ e-mail:fci@Karpov.IPC.ru \\ Received April 22, 2010
}

DOI: $10.1134 / \mathrm{S} 0018143910060147$

In most facilities with isotope sources designed for radiation-chemical studies, irradiators are composed of tubular elements (rods). When the rod diameter is significantly smaller than the distance to an irradiated object, the irradiator can be treated as linear and, hence, the conventional equations $[1,2]$ can be used for dose rate calculations.

The dose rate distribution along the length of the rod is not uniform even at a constant linear density of radioactivity in the elements, thereby complicating to a considerable extent the calculation of radiationchemical facilities. Below, we present the relationship derived for the averaged dose rate along the length of a linear source. The dose rate distribution along the length of an unshielded source is as follows [1]:

$$
P(R, s)=\frac{K \gamma}{s}\left[\operatorname{arctg} \frac{(L-R)}{s}+\operatorname{arctg} \frac{(L+R)}{s}\right],
$$

where $K$ is the gamma-constant of the isotope, $\gamma$ is the linear activity density, and $s=\sqrt{h^{2}+c^{2}}$. Values for the other quantities are given in the figure borrowed from [1]. The length-averaged dose rate at a distance $s$ from the source is as follows:

$$
\begin{gathered}
\bar{P}(s)=\frac{1}{2 L} \int_{-L}^{+L} P(R, s) d R \\
=\frac{K \gamma}{L s}\left[\int_{0}^{L} \operatorname{arctg} \frac{(L-R)}{s} d R+\int_{0}^{L} \operatorname{arctg} \frac{(L+R)}{s} d R\right] .
\end{gathered}
$$

The integrals in Eq. (2) are easy to reduce to a tabular form [3] using new variables $U=\frac{L-R}{S}$ and $V=$ $\frac{L+R}{s}$ [3]. After the necessary transformations, we obtain

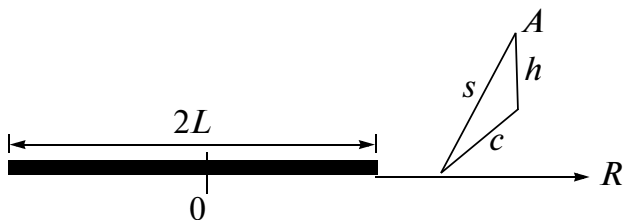

Geometry of a linear source (in relation to calculation of the dose rate at point $A$ ).

$$
\bar{P}(s)=\alpha\left[\frac{2}{s} \operatorname{arctg}(\beta)-\frac{1}{2 L} \operatorname{Ln}\left(1+\beta^{2}\right)\right],
$$

where $\alpha=K \gamma ; \beta=2 L / s$.

Equation (3) substantially simplifies the computation procedure for radiation-chemical devices. We have successfully used it for calculation of both the average absorbed dose in a stirred liquid system in cylindrical reactors and the transient dose in objects moving in a radiation field of flat irradiators based on rods.

\section{REFERENCES}

1. Ivanov, V.I. and Mashkovich, V.P., Sbornik zadach po dozimetrii $i$ zashchite ot ioniziruyushchikh izluchenii (Problems on Dosimetry and Radiation Protection), Moscow: Atomizdat, 1980.

2. Rukovodstvo po radiatsionnoi zashchite dlya inzhenerov (Engineer's Manual on Radiation Shielding), Moscow: Atomizdat, 1973, vol. 2.

3. Spravochnik po spetsial'nym funktsiyam (A Handbook of Special Functions) Abramovits, M. and Stigan, I., Eds., Moscow: Nauka, 1979, p. 47. 